\title{
Article \\ Study on the Effect of Deposited Graphene Oxide on the Fatigue Life of Austenitic Steel 1.4541 in Different Temperature Ranges
}

\author{
Barbara Nasiłowska ${ }^{1, *(1)}$, Zdzisław Bogdanowicz ${ }^{2}$, Paweł Bogusz ${ }^{2}$ (I) , Aneta Bombalska ${ }^{1}$ (I) \\ and Zygmunt Mierczyk ${ }^{1} \mathbb{D}$ \\ 1 Institute of Optoelectronics, Military University of Technology, gen. S. Kaliskiego 2, 00-908 Warsaw, Poland; \\ aneta.bombalska@wat.edu.pl (A.B.); zygmunt.mierczyk@wat.edu.pl (Z.M.) \\ 2 Faculty of Mechanical Engineering, Military University of Technology, gen. S. Kaliskiego 2, 00-908 Warsaw, Poland; \\ zdzislaw.bogdanowicz@wat.edu.pl (Z.B.); pawel.bogusz@wat.edu.pl (P.B.) \\ * Correspondence: barbara.nasilowska@wat.edu.pl
}

check for

updates

Citation: Nasiłowska, B.;

Bogdanowicz, Z.; Bogusz, P.;

Bombalska, A.; Mierczyk, Z. Study on the Effect of Deposited Graphene Oxide on the Fatigue Life of Austenitic Steel 1.4541 in Different Temperature Ranges. Materials 2022, 15, 65. https://doi.org/10.3390/ ma15010065

Academic Editor: Daniel Casellas

Received: 12 November 2021

Accepted: 20 December 2021

Published: 22 December 2021

Publisher's Note: MDPI stays neutral with regard to jurisdictional claims in published maps and institutional affiliations.

Copyright: (C) 2021 by the authors. Licensee MDPI, Basel, Switzerland. This article is an open access article distributed under the terms and conditions of the Creative Commons Attribution (CC BY) license (https:// creativecommons.org/licenses/by/ $4.0 /)$.

\begin{abstract}
This paper presents the effect of deposited graphene oxide coating on fatigue life of austenitic steel 1.4541 at $20{ }^{\circ} \mathrm{C}, 100{ }^{\circ} \mathrm{C}$, and $200{ }^{\circ} \mathrm{C}$. The study showed a decrease in the fatigue life of samples with a deposited graphene oxide layer in comparison with reference samples at $20^{\circ} \mathrm{C}$ and $100^{\circ} \mathrm{C}$. However, an increase in fatigue life of samples with a deposited graphene oxide layer in comparison with reference samples occurred at $200{ }^{\circ} \mathrm{C}$. This relationship was observed for the nominal stress amplitude of 370 and $420 \mathrm{MPa}$. Measurements of temperature during the tensile failure of the sample and microfractographic analysis of fatigue fractures were performed. Tests have shown that graphene oxide deposited on the steel surface provides an insulating layer. A higher temperature of the samples with a deposited graphene oxide layer was observed during fracture compared to the reference samples.
\end{abstract}

Keywords: graphene oxide; austenitic steel; steel 1.4541; fatigue life

\section{Introduction}

Improvements in mechanical properties after the addition of graphene or its derivatives to composites have resulted from many research projects [1-4]. The results of fatigue life studies presented in work by Demir et al. [2], Rafiee et al. [3], and Li et al. [4], among others, have shown that a small addition of graphene or its derivatives in the volume of a composite results in an improvement in its mechanical properties.

Li et al. [4] showed that the addition of \%wt. 0.075 multilayer graphene into concrete fills the voids in the porous structure, leading to a $49.3 \%$ increase in fatigue life. Moreover, the content of $\sim 0.2 \%$ graphene in a composite consisting of epoxy fibers increases the flexural fatigue life by up to 1200 times [3]. Yavari et al. [5] showed that addition of graphene caused a $\sim 3-5$-fold increase in the fatigue life of fiberglass/epoxy composites.

Najfi et al. [6] conducted an analysis of the effect of graphene oxide functional groups on fatigue strength. They indicated that graphene oxide with a low degree of functionalization $(<15 \%)$ exhibited a significantly higher fatigue life compared to graphene. The addition of ether groups resulted in delayed crack growth and increased fatigue strength [6].

Taking into account the increase in fatigue life of composites containing graphene [2-7] and its structural properties, including a high fracture strength of $125 \mathrm{GPa}$ [7], the effect of a deposited layer of graphene and its derivatives on the mechanical properties of structural materials is an interesting research issue. Studies presented in [1] have shown that deposition of graphene oxide on the surface of St3S steel can contribute to an increase in corrosion resistance.

Currently, the most well-known method for depositing graphene on the surface of (mainly) copper is chemical vapor deposition (CVD) [8-10]. However, in many research centers, there are attempts to deposit graphene and its derivatives on the surface of construction materials using other methods, such as those with the use of an aerosol [11]. 
Studies performed on 304 steel bolts showed that hybrid graphenation (shot peening of a graphene layer deposited on the steel surface) leads to an increase in fatigue life of $42-275 \%$ (depending on the stress amplitude level) [12].

However, to date, fatigue life tests at elevated temperatures $\left(20{ }^{\circ} \mathrm{C}, 100{ }^{\circ} \mathrm{C}\right.$, and $\left.200{ }^{\circ} \mathrm{C}\right)$ of flat specimens made of 1.4541 steel with a deposited graphene oxide (GO) layer have not been performed. Therefore, taking into account the operation of many machine parts and structural elements at elevated temperatures, the aim of this work was to determine the effect of a deposited graphene oxide layer on mechanical properties.

\section{Materials and Methods}

Static tension tests and fatigue life tests were performed on flat paddle specimens of $5 \mathrm{~mm}$ thickness made of 1.4541 steel according to the following designations: BM-base material (as supplied) (Section 2.1), and BM + GO-base material with a deposited graphene oxide layer (Sections 2.1-2.3).

\subsection{Steel 1.4541}

The dumbbell specimens (Figure 1) were made of 1.4541 steel (according to the designations EN 1.4541, PN 1H18N10T, AISI 321, X5CrNi18-10, SS 2337), whose percentage content of alloying elements was as follows: Ni 9.0-12.0; Cr 17.0-19.0; $\mathrm{Mn}<2.0 ; \mathrm{C}<0.08$; $\mathrm{Si}<1.0 ; p<0.045 ; \mathrm{S}<0.015 ; \mathrm{T}<0.70 ;$ and $\mathrm{Fe}=$ bal. Test specimens were cut by the Water jet method from a $2000 \times 1000 \times 5 \mathrm{~mm}^{3}$ metal sheet perpendicular to the rolling direction. The inner edges of the specimens were subjected to a milling process as shown in Figure 1.

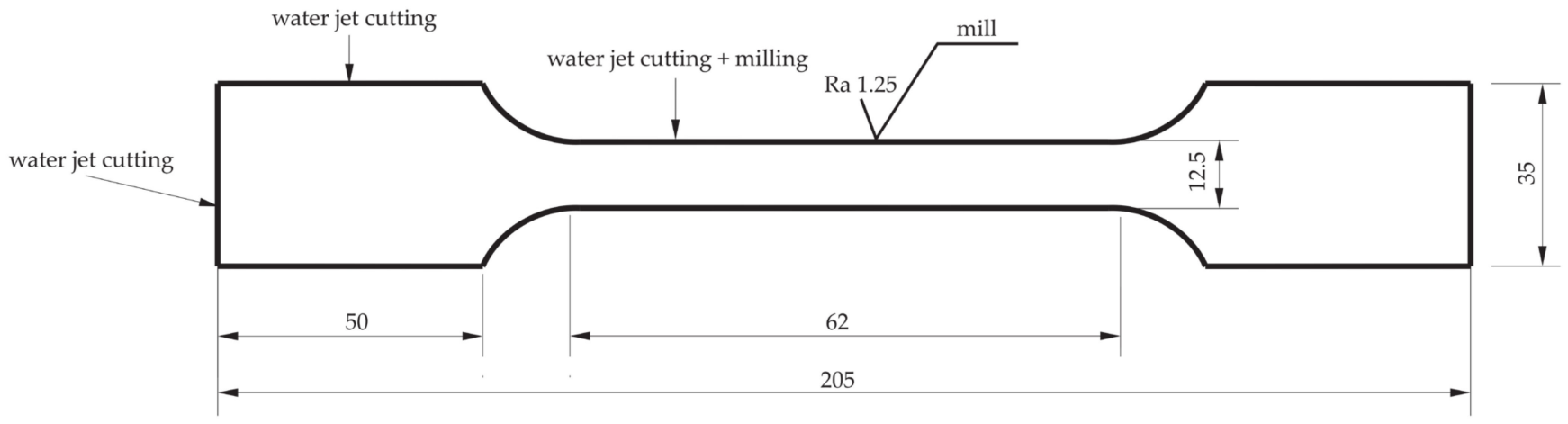

Figure 1. Dimensions (mm) of BM (Base Material) and BM + GO (Base Material + Graphene Oxide) samples subjected to mechanical and fatigue testing.

\subsection{Graphene Oxide (GO)}

Graphene oxide (GO) flakes dispersed in water were obtained from flake graphite by a modified Hummers method (Department of Chemical Synthesis and Flake Graphene, Łukasiewicz Research Network-Institute of Electronic Materials Technology, Warsaw, Poland). The concentration of graphene oxide water dispersion was $10 \mathrm{~g} / \mathrm{L}$. Flake size was 3-10 $\mu \mathrm{m}$. The detailed synthesis method was described previously in [11-13].

\subsection{Methodology of Deposition of the Graphene Oxide on the Surface}

In the first step of graphene oxide deposition on BM + GO samples, surface activation and cleaning with RF (radio frequency) plasma was performed using a Plasma Prep III device (Garfield Ave, West Chester, PA, USA) (Figure 2a). The following parameters were used: $100 \mathrm{~W}$ for $30 \mathrm{~min}$. The interaction of the plasma with the steel surface causes an increase in hydrophilicity $[14,15]$ so that the aqueous suspension better wets the steel surface promoting the dissolution of graphene oxide flakes on the surface. This process, in addition to cleaning the surface, is aimed at the adhesive incorporation of graphene oxide particles into the surface layer of steel. Immediately after removal from the plasma 
chamber, the samples were placed in a Petri dish with a dispersed graphene oxide aqueous suspension for $10 \mathrm{~min}$ (Figure 2b). In the last step, the excess suspension was removed mechanically and the samples were placed in a vacuum dryer Vacucell 22 L (BMT Medical Technology s.r.o., Brno-Zábrdovice, Czech Republic) at $40{ }^{\circ} \mathrm{C}$ for $24 \mathrm{~h}$ (Figure 2c).

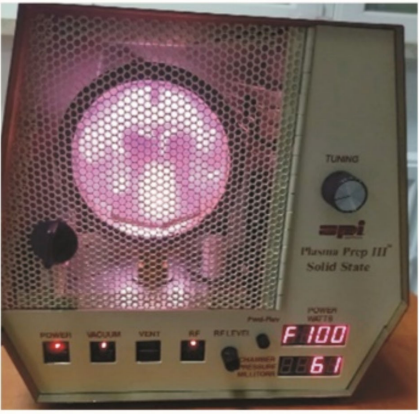

(a)

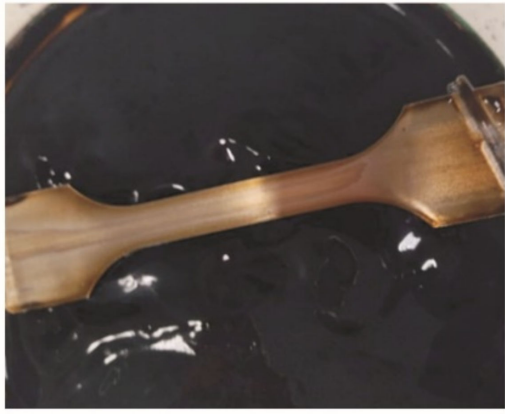

(b)

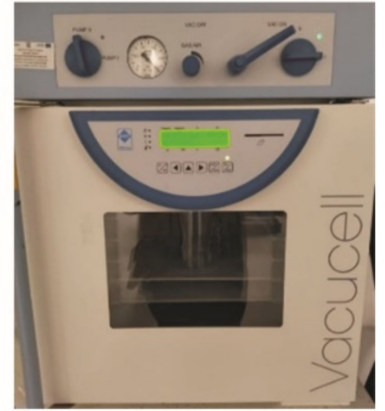

(c)

Figure 2. Deposition process of graphene oxide on BM + GO samples; activation and plasma purification (a), immersion in dispersed graphene oxide aqueous suspension (b), vacuum drying (c).

\subsection{Static and Fatigue Tensile Tests}

Static tensile and fatigue tests were performed using an Instron 8862 (Norwood, MA, USA) electromechanically driven testing machine with a force range of $\pm 100 \mathrm{kN}$ (Figure 3a) coupled to a climate chamber (Figure 3b). An Instron model 2620-604 extensometer (Norwood, MA, USA) was used to measure strain, with a $25 \mathrm{~mm}$ measurement base. The tests were performed at temperature levels of 20,100 , and $200^{\circ} \mathrm{C}$ for $\mathrm{BM}$ and $\mathrm{BM}+\mathrm{GO}$ samples.

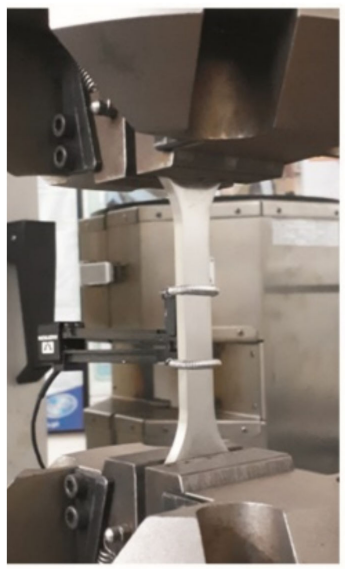

(a)

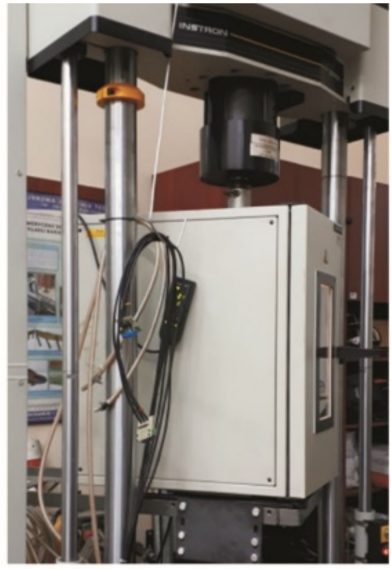

(b)

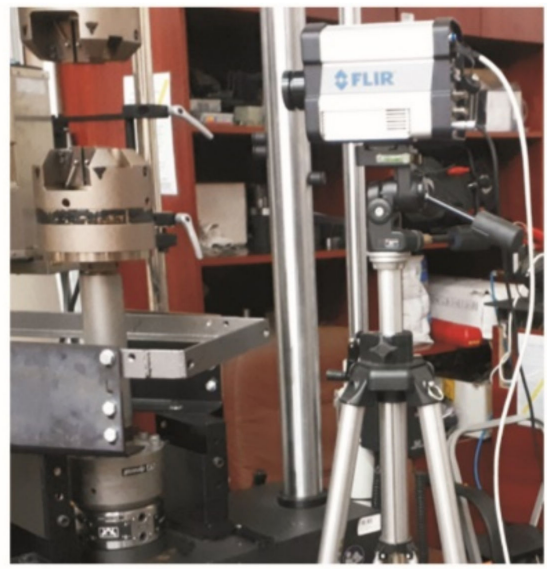

(c)

Figure 3. Instron 8862 test stand (a), climate chamber (b) FLIR SC6000 camera (c).

Table 1 shows the values of the maximum stress (in $\mathrm{MPa}$ ) and the maximum, minimum, mean, and amplitude of the stress cycle applied to the test specimens (in $\mathrm{kN}$ ). 
Table 1. Fatigue test load levels (Rm-Ultimate tensile strength).

\begin{tabular}{ccccc}
\hline \multirow{2}{*}{ Fatigue Test Parameters } & \multicolumn{4}{c}{ Load Levels } \\
\cline { 2 - 5 } & $\mathbf{R m}=\mathbf{0 . 9}$ & $\mathbf{R m}=\mathbf{0 . 8}$ & $\mathbf{R m}=\mathbf{0 . 7}$ & $\mathbf{R m}=\mathbf{0 . 6}$ \\
\hline Maximum stress $(\mathrm{MPa})$ & 540.1 & 500.0 & 420.0 & 370.0 \\
Maximum force $(\mathrm{kN})$ & 33.66 & 31.16 & 26.18 & 23.06 \\
Minimum force $(\mathrm{kN})$ & 3.37 & 3.12 & 2.62 & 2.31 \\
Average force $(\mathrm{kN})$ & 18.51 & 17.14 & 14.40 & 12.68 \\
Amplitude of cycle load $(\mathrm{kN})$ & 15.15 & 14.02 & 11.78 & 10.38 \\
\hline
\end{tabular}

Fatigue tests were carried out for different stress levels $\mathrm{Rm}=0.6,0.7,0.8$, and 0.9 at maximum stress levels of 370, 420,500, and $540 \mathrm{MPa}$ respectively (Table 1 ). The cycle asymmetry factor was $\mathrm{R}=0.1$, while the load frequency was $1 \mathrm{~Hz}$.

During static and fatigue measurements at $20{ }^{\circ} \mathrm{C}$, the temperature distribution was performed using a FLIR (Teledyne FLIR, Wilsonville, OR, USA) model SC6000 thermal imaging camera (Figure 3c). The camera distance from the sample was approximately $0.6 \mathrm{~m}$. The pictures were taken at full camera resolution of $640 \times 320$ pixels. The emissivity coefficients of the tested samples were determined by comparing the measurement of the average temperature on the surface of each sample measured by the thermal imaging camera with the actual value of the temperature set in the climatic chamber.

\subsection{Characterization Surface Morphology}

\subsubsection{Scanning Electron Microscopy}

Graphene oxide deposited on screw was investigated by scanning electron microscopy (SEM) using a Quanta 250 FEG SEM, FEI, Hillsboro, OR, USA. SEM images were acquired using a backscattered detector (ETD-BSE, FEI, Hillsboro, OR, USA) with an accelerating voltage of $2-5 \mathrm{kV}$ for $\mathrm{GO}$ and $5-10 \mathrm{kV}$.

\subsubsection{Confocal Microscopy}

The measurements of the changes in surface roughness of stainless steel 1.4541 as a result of plasma cleansing and GO deposition were made using a confocal microscope Zeiss LSM 700 (Carl Zeiss Microscopy, Jena, Germany). The experimental parameters were laser wavelength $405 \mathrm{~nm}$, pinhole $0.5 \mathrm{AU}$ (Airy Unit), and gain $416 \mathrm{~nm}$. Five measurements for each sample were made.

\subsubsection{Fourier-Transform Infrared Spectroscopy}

Measurements of the spectra of GO in the infrared range were made using the FTIR technique in reflection mode. The measurements were made to confirm GO deposition on the stainless steel 1.4541 surface (BM). For FTIR measurements, a Thermo Scientific Nicolet iN10 with a DTGS detector (ThermoFisher SCIENTIFIC, Waltham, MA, USA) was used. Spectra were recorded nine times in different locations with 126 scans in a range of $675-4000 \mathrm{~cm}^{-1}$ with a resolution of $4 \mathrm{~cm}^{-1}$.

\section{Results}

\subsection{Surface Morphology}

The analysis of the surface morphology of BM (Figure 4a) and BM + GO (Figure 4b) samples showed that graphene oxide flakes fill and smooth the structural notches, i.e., cracks formed during the sheet rolling process. As a result, a reduction in surface roughness after graphene oxide deposition of about $21.9 \%\left(\mathrm{Ra}^{1}\right)$ and $32.8 \%\left(\mathrm{Rz}^{2}\right)$ was observed (Table 2). 


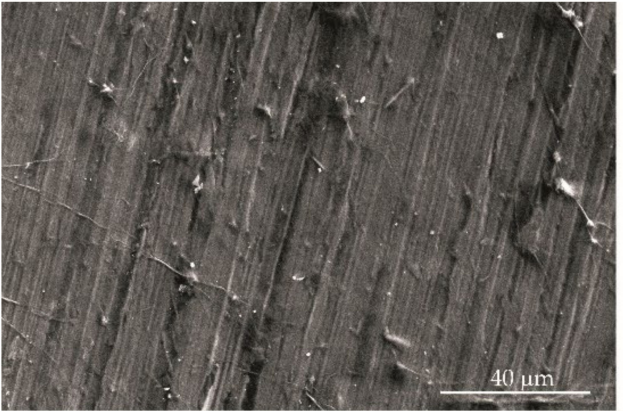

(a)

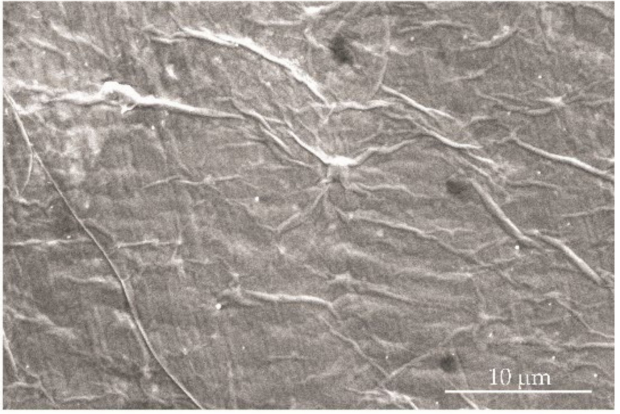

(b)

Figure 4. SEM (Scanning Electron Microscope) images of the surface of BM (a) and BM + GO (b) samples.

Table 2. Surface roughness of BM and BM + GO (Base Material + Graphene Oxide) samples (mean of 5 measurements) with standard deviation.

\begin{tabular}{ccc}
\hline Surface Type & Mean Value $\mathbf{R a}^{\mathbf{1}}(\boldsymbol{\mu \mathbf { m }})$ & ${\text { Mean Value } \mathbf{R z}^{\mathbf{2}}(\boldsymbol{\mu m})}$ \\
\hline BM & $1.12 \pm 0.27$ & $6.15 \pm 1.59$ \\
BM + GO & $0.895 \pm 0.16$ & $4.13 \pm 0.35$ \\
\hline
\end{tabular}

${ }^{1}$ Ra-arithmetic average. ${ }^{2}$ Rz-maximum peak to valley height of the profile.

In order to confirm the presence of graphene oxide on the surface of austenitic steel 1.4541, FTIR studies were performed which showed a positive result when applying GO on the surface $(\mathrm{BM}+\mathrm{GO})$. Figure 5 shows typical absorption bands characteristic for oxidized domains of GO [16].

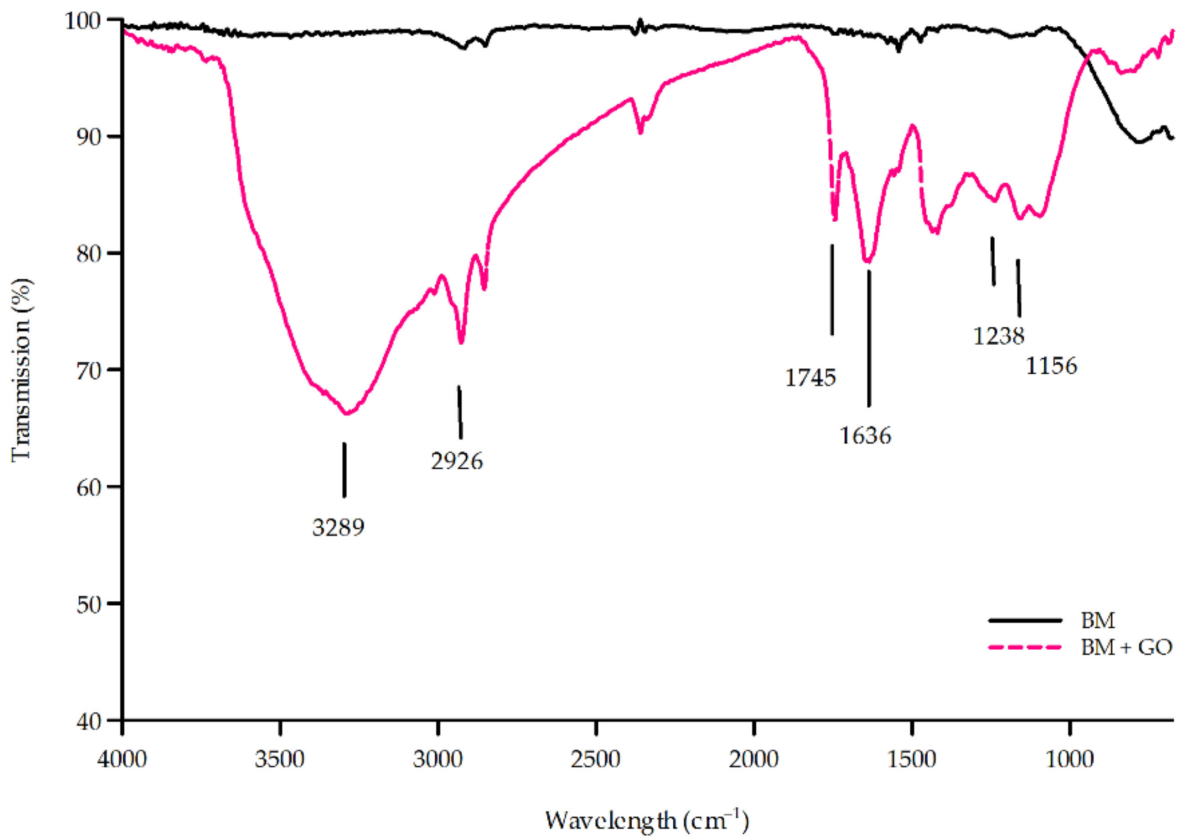

Figure 5. FTIR (Fourier-transform Infrared Spectroscopy) spectra of the BM and BM + GO samples.

The GO samples (BM + GO) have absorption peaks at $3289 \mathrm{~cm}^{-1}, 2976 \mathrm{~cm}^{-1}, 1745 \mathrm{~cm}^{-1}$, $1636 \mathrm{~cm}^{-1}, 1238 \mathrm{~cm}^{-1}$, and $1156 \mathrm{~cm}^{-1}$ corresponding to the vibrations of the $\mathrm{C}-\mathrm{O}$ bond, $\mathrm{C}=\mathrm{C}$ bond, $\mathrm{C}=\mathrm{O}$ bond, aliphatic $\mathrm{C}-\mathrm{H}$, and $\mathrm{O}-\mathrm{H}$ bond, respectively. This shows that the surfaces examined have oxygen-containing groups in the $\mathrm{BM}+\mathrm{GO}$ sample, which proves successful deposition of the GO as compared to the BM sample spectrum. 


\subsection{Static Tensile Tests}

Static tensile tests were performed for three temperature levels 20,100 , and $200{ }^{\circ} \mathrm{C}$. The mean results of the five trials along with the standard deviations are listed in Table 3. A decrease (occurring at the limit of statistical error) in the values of tensile strength $\mathrm{Rm}$ (1.53-2.56\%), yield strength Re (2.97-5.65\%), and Young's modulus E (2.93-8.89\%) was observed in all the samples tested in comparison with the untreated ones. The exception was an $8.89 \%$ decrease in the elastic modulus at $200{ }^{\circ} \mathrm{C}$ of $\mathrm{BM}+\mathrm{GO}$ samples compared to BM samples.

Table 3. Static tensile test results.

\begin{tabular}{ccccc}
\hline Sample Type & $\begin{array}{c}\text { Temperature } \\
\left({ }^{\circ} \mathbf{C}\right)\end{array}$ & $\begin{array}{c}\text { Tensile Strength } \\
\text { Limit } \\
\text { Rm (MPa) }\end{array}$ & $\begin{array}{c}\text { Young's } \\
\text { Modulus } \\
\text { E (MPa) }\end{array}$ & $\begin{array}{c}\text { Yield Strength } \\
\text { Re (MPa) }\end{array}$ \\
\hline \multirow{2}{*}{ BM } & 20 & $600.1 \pm 1.5$ & $196,156.9 \pm 4697$ & $350.7 \pm 2.5$ \\
& 100 & $527.5 \pm 10.2$ & $194,624.6 \pm 8359$ & $325.7 \pm 14.3$ \\
& 200 & $464.5 \pm 0.4$ & $194,332.8 \pm 8065$ & $292.0 \pm 1.0$ \\
\hline \multirow{3}{*}{ BM+GO } & 20 & $590.9 \pm 1.9$ & $190,415.2 \pm 5253$ & $340.3 \pm 2.5$ \\
& 100 & $514.0 \pm 3.0$ & $188,717.4 \pm 1259$ & $307.3 \pm 2.1$ \\
& 200 & $453.2 \pm 1.7$ & $177,055.6 \pm 1164$ & $282.0 \pm 2.6$ \\
\hline
\end{tabular}

The maximum temperature during the static tensile test at the point of breakage was 9.4\% lower for BM specimens as compared to BM + GO specimens. It was also observed that after tensile failure, the cooling process of $\mathrm{BM}+\mathrm{GO}$ samples was faster (Figure 6). The recorded difference is probably due to the blocking of heat propagation by the graphene flake layer.

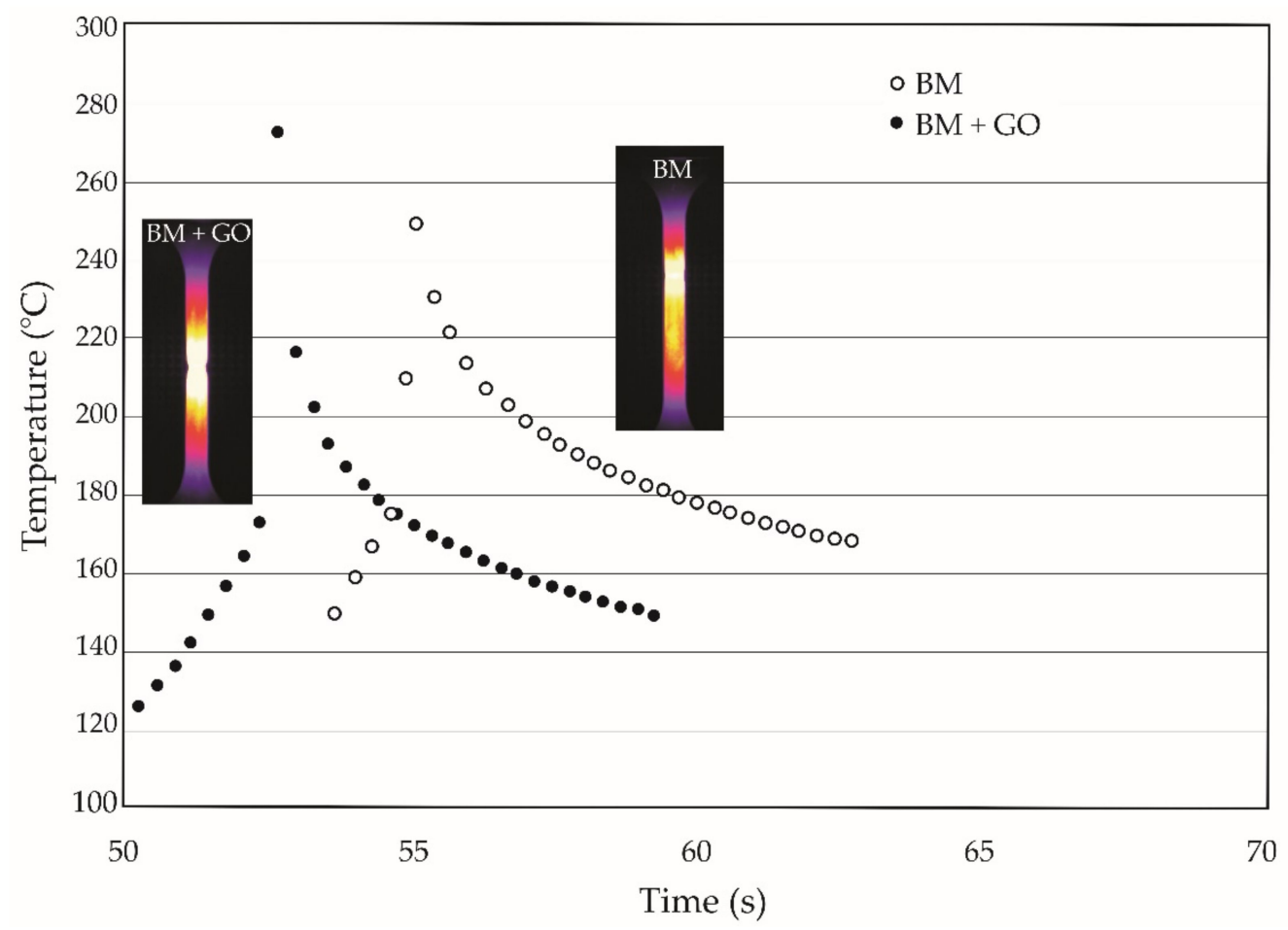

Figure 6. Temperature distribution during static tensile failure test of $\mathrm{BM}$ and $\mathrm{BM}+\mathrm{GO}$.

\subsection{Fatigue Tensile Tests}

Fatigue life tests (at 20, 100 and $200{ }^{\circ} \mathrm{C}$ ) were performed at $\sigma_{\max }$ levels of $0.9,0.8,0.7$, and 0.6 Rm (540, 500, 420 and $370 \mathrm{MPa})$. The material strength limit Rm was determined 
experimentally and was $600 \mathrm{MPa}$ (Table 3). For elevated temperature tests, the tensile strength limit Rm must be higher than the specified cycle stress. Thus, the fatigue life was not tested at 0.9 for specimens tested at $100{ }^{\circ} \mathrm{C}$ and 0.9 and 0.8 for specimens tested at $200{ }^{\circ} \mathrm{C}$.

Averaged results of fatigue life tests (from four measurements) in the temperature range of 20,100 , and $200{ }^{\circ} \mathrm{C}$ were used to prepare the Wohler diagram (Figure 7 ).

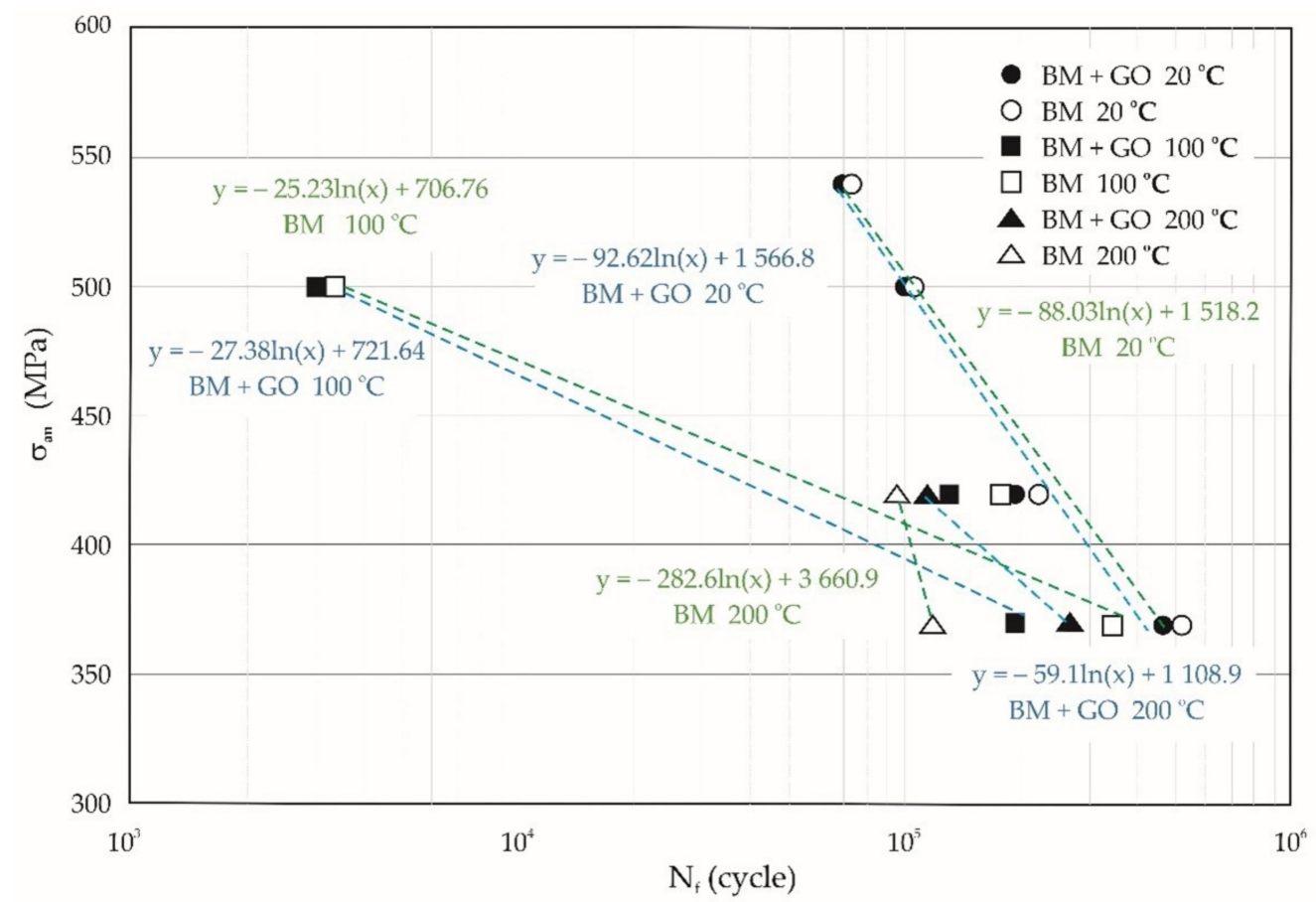

Figure 7. Wöhler plot of the limited range of $\mathrm{BM}$ and $\mathrm{BM}+\mathrm{GO}$ samples at different temperature ranges of 20,100 , and $200{ }^{\circ} \mathrm{C}$.

No significant effect of graphene oxide deposition on fatigue life was observed at $20^{\circ} \mathrm{C}$. Test results obtained at $20^{\circ} \mathrm{C}$, presented as curves in Figure 7 , show a slight $(12 \%(370 \mathrm{MPa})$, $14 \%(420 \mathrm{MPa}), 2 \%(500 \mathrm{MPa}))$ increase in fatigue life of BM specimens in comparison with $\mathrm{BM}+\mathrm{GO}$ specimens. The difference in fatigue life of BM specimens compared to $\mathrm{BM}+\mathrm{GO}$ specimens tested at $100{ }^{\circ} \mathrm{C}$ was much higher at $77 \%(370 \mathrm{MPa}), 37 \%(420 \mathrm{MPa})$, and $8 \%(500 \mathrm{MPa})$. However, surprising results on the lifetime of $\mathrm{BM}+\mathrm{GO}$ samples were obtained at $200{ }^{\circ} \mathrm{C}$. The tests showed that the fatigue life at $200{ }^{\circ} \mathrm{C}$ of $\mathrm{BM}+\mathrm{GO}$ specimens is higher than that of BM specimens by $135 \%$ and $21 \%$ at nominal stress amplitudes of 370 and $420 \mathrm{MPa}$, respectively.

In Figure 8 the curves of fatigue life changes with respect to temperature at 20,100, and $200{ }^{\circ} \mathrm{C}$ performed at a maximum stress level $\sigma_{\max }$ of 370 and $420 \mathrm{MPa}$ are presented. At $20^{\circ} \mathrm{C}$ and $100{ }^{\circ} \mathrm{C}$, an increase in the fatigue life of BM specimens compared to $\mathrm{BM}+\mathrm{GO}$ was observed. However, at $200{ }^{\circ} \mathrm{C}$ the opposite situation was observed. There was an increase in the fatigue life of BM + GO samples compared to BM samples. In general, the study showed that as the temperature increases, the fatigue life of BM specimens decreases, in contrast to $\mathrm{BM}+\mathrm{GO}$ specimens. This may be due to the change in the structural properties of graphene oxide flakes as a result of temperature changes and variable loads. 


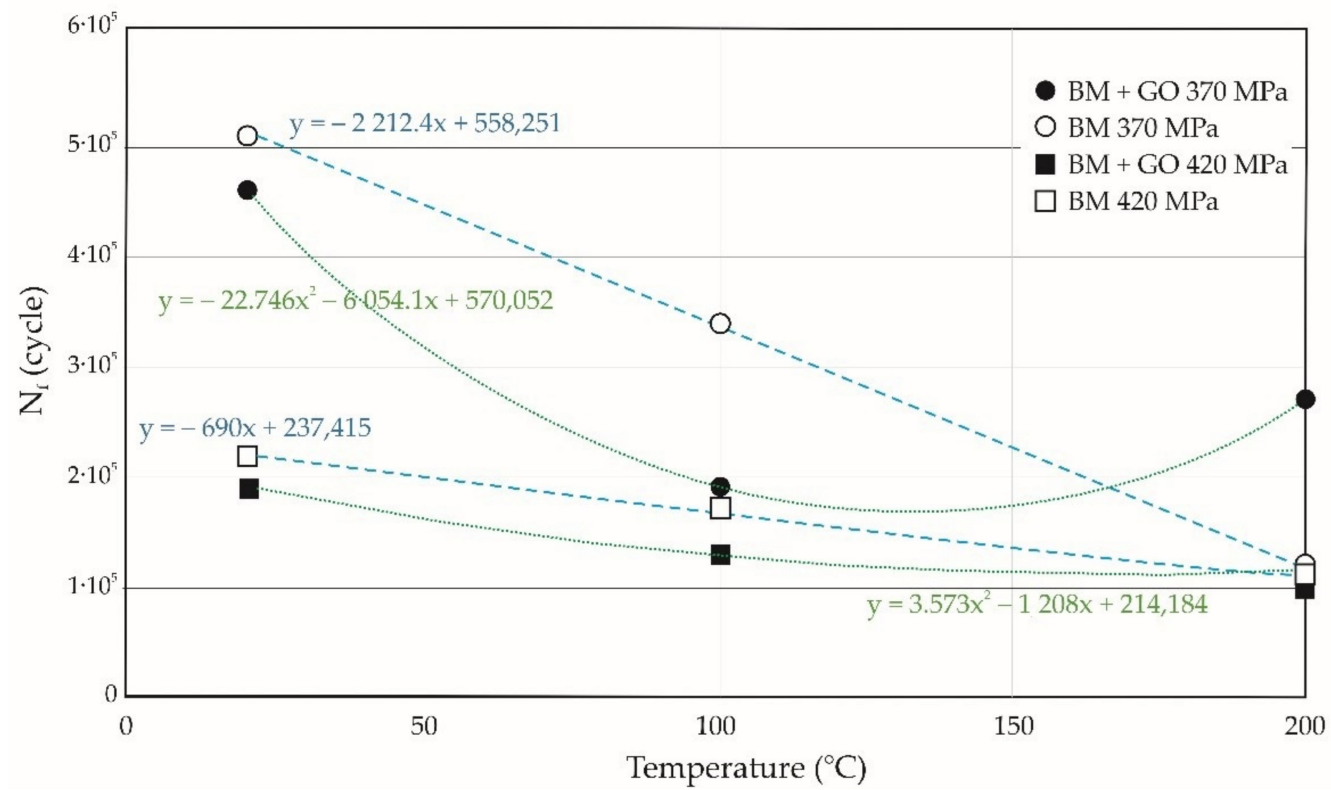

Figure 8. Fatigue life of specimens with and without deposited graphene oxide at 20, 100, and $200{ }^{\circ} \mathrm{C}$ performed for maximum stresses of 370 and $420 \mathrm{MPa}$.

During the fatigue life tests, a higher temperature of $3-26 \%$ of the $B M+G O$ specimens was also observed in comparison with BM specimens during final failure. The deposited graphene oxide layer provided an insulating layer, which made the sample heat up more slowly (Figure 9).

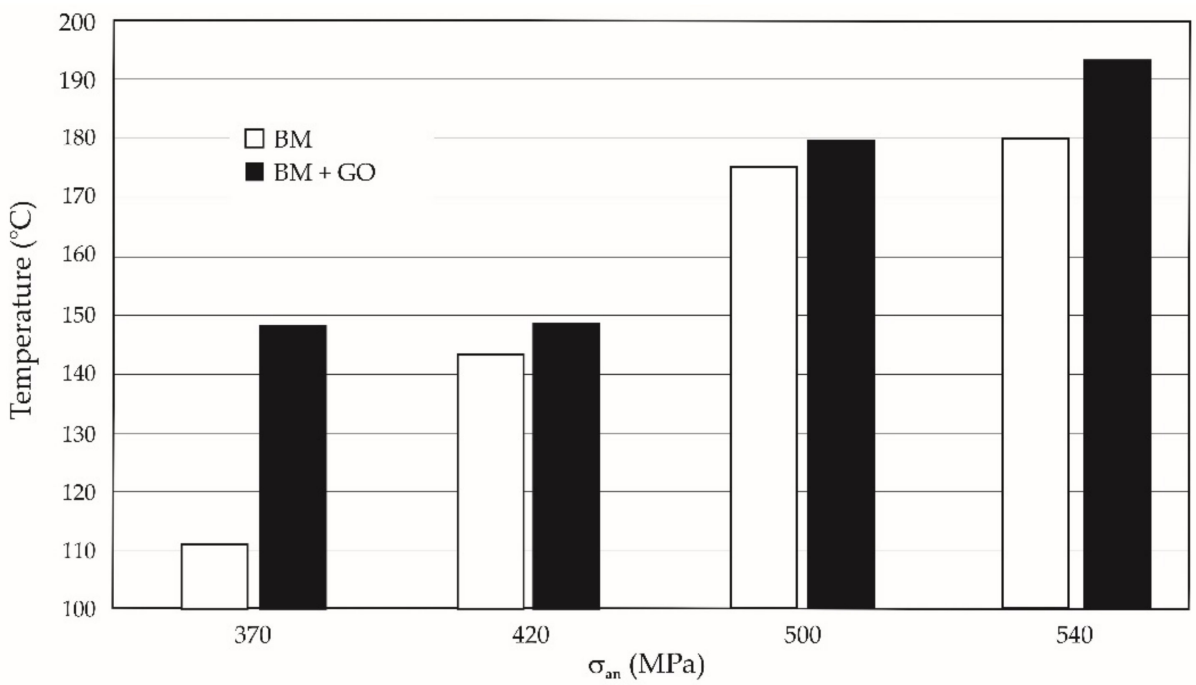

Figure 9. Temperature difference during fatigue rupture of $\mathrm{BM}$ and $\mathrm{BM}+\mathrm{GO}$ samples.

\subsubsection{Microfractography of Fatigue Fracture Surfaces}

Microfractography of the surface of fatigue fractures of BM specimens and $\mathrm{BM}+\mathrm{GO}$ specimens observed by scanning electron microscopy SEM revealed the sites of crack initiation (Figure 10a,e), steady-state crack development (Figure 10b,c,f,g), and pits in the residual zone (Figure 10d,h). Unifocal fatigue crack initiation (1) of BM (Figure 10a-d) and $\mathrm{BM}+\mathrm{GO}$ (Figure 10e-h) samples occurred similarly-mainly at the edge of the samples (Figure 10a,e). 


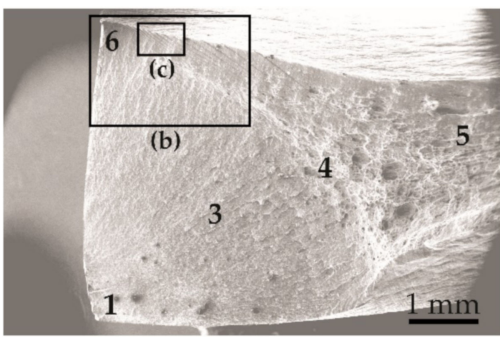

(a)

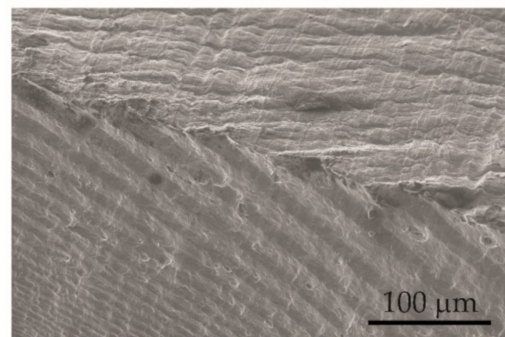

(c)

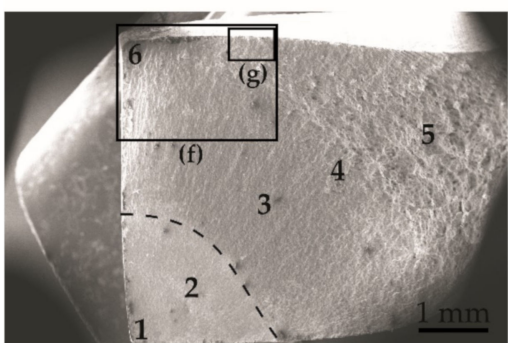

(e)

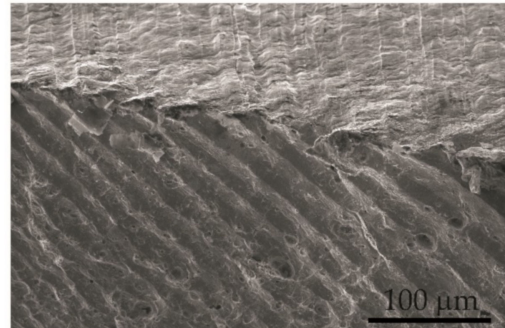

(g)

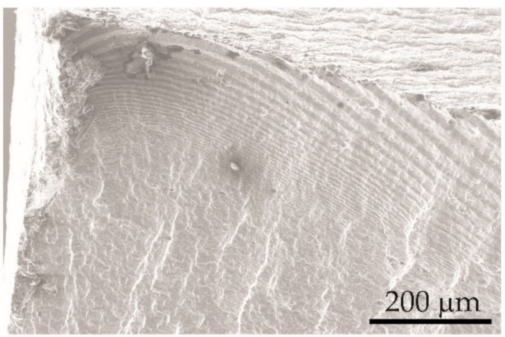

(b)

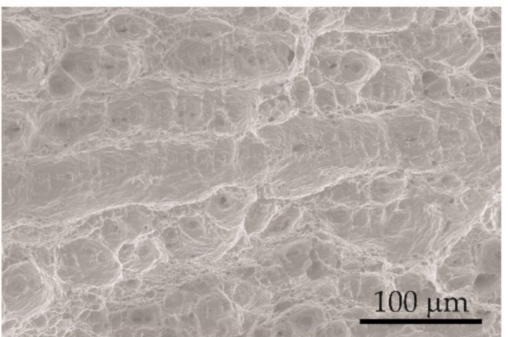

(d)

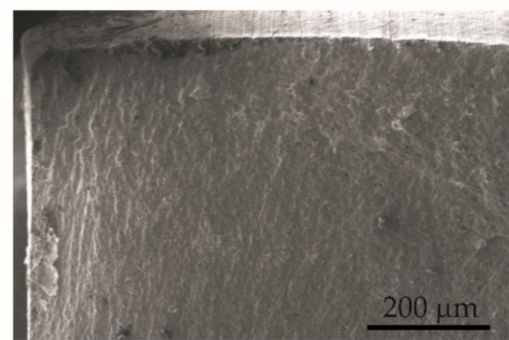

(f)

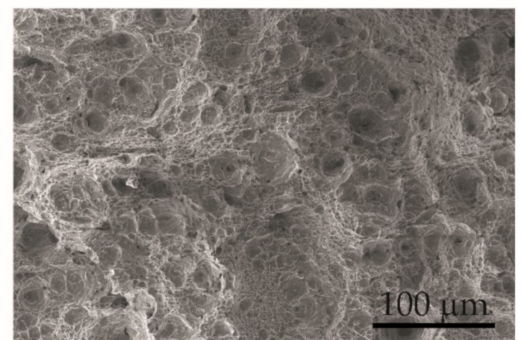

(h)

Figure 10. Microfractography of the fatigue fracture of BM (a-d) and BM + GO (e-h) samples. Singlefocus fatigue crack initiation (1), focal zone (2), fatigue zone (3), transition zone (4), residual zone (5), faults (6).

Microfractography analysis of the fatigue fractures showed a shiny zone (2) around the fracture initiation focus in the $\mathrm{BM}+\mathrm{GO}$ specimens. The next stage of sample failure was the transition zone (4) separating the fatigue zone (3) from the residual zone (5), where rapid specimen damage occurred [17]. On the opposite side to the crack initiation site, faults appeared (6) (Figure 10b,f). However, they were more pronounced on the lateral edge for BM samples (Figure 10a,b) than for BM + GO samples (Figure 10e,f). This may have been due to the reduction in surface roughness of the samples after graphene oxide deposition (Section 3.1). However, at a distance of about $1 \mathrm{~mm}$ from the lateral edge of the fracture, faults were visible for both types of samples, BM (Figure 10c) and BM + GO (Figure 10g).

The final stage of damage occurred as a consequence of the separation characteristic for static cracking (Figure 10d,h). There was an increase in cavities and craters (BM-Figure 10d and BM + GO-Figure 10h). Observation of the sample shows that in the hollow zone the breakthroughs were of a typically ductile character and so-called 
honeycombs were formed. The craters located in the center of the sample were large and oval, while at the edge of the sample the residual zone was elongated and characterized by a smaller depth.

\subsubsection{Microfractography of Graphene Oxide Cracks on the Steel Surface}

The deposited graphene oxide flakes formed a uniform surface on the BM $+\mathrm{GO}$ samples (Figure 11a). In the initial stage of fatigue cycling during the tests, extrusionshaped lines arranged perpendicular to the force of the fatigue machine actuator and parallel to the fracture front were visualized on the surface of graphene flakes (Figure 11b). Then, as the number of cycles increased, parallel cracks of the deposited graphene oxide layer occurred at the extrusion sites (Figure 11c,d). This probably affects the performance properties (strength, durability, temperature changes) of the BM+ GO samples.

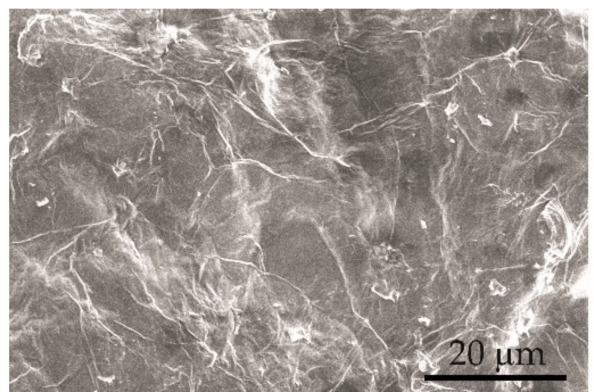

(a)

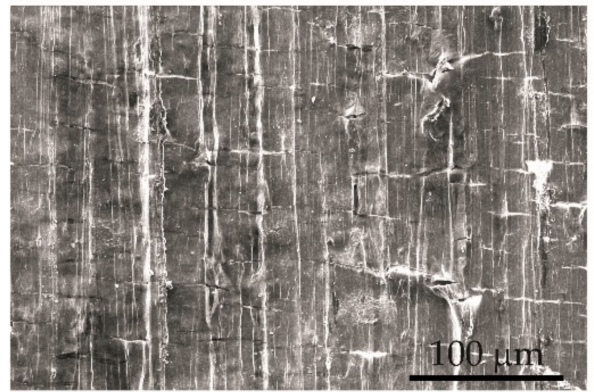

(c)

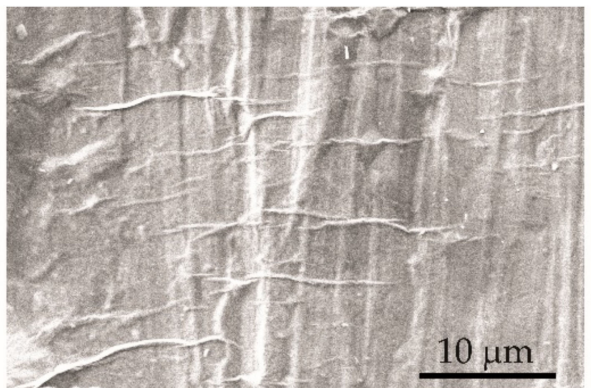

(b)

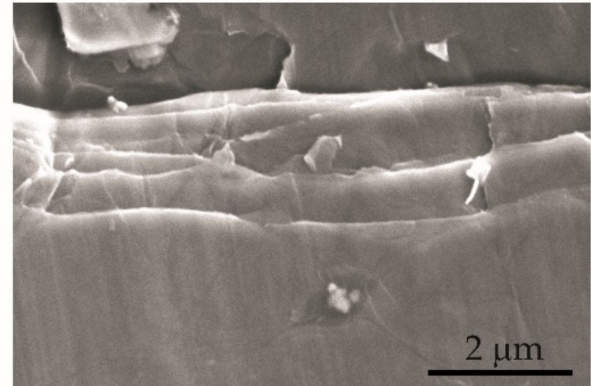

(d)

Figure 11. Microfractography of deposited graphene oxide on the surface of steel $1.4541 \mathrm{BM}+\mathrm{GO}$ specimens during fatigue tests. Before (a) during $(\mathbf{b}, \mathbf{c})$ and after the tests $(\mathbf{d})$.

\section{Discussion}

The graphene oxide coating applied on flat samples made of 1.4541 steel had a positive effect on surface smoothing. The arithmetic mean of the profile deviation $(\mathrm{Rz}$-maximum peak to valley height of the profile) for $\mathrm{BM}+\mathrm{GO}$ was $32.8 \%$ lower than for BM samples (without GO coating) (Figure 4). It was observed that the deposited GO layer on the specimens was generally durable. However, at the final stage of fatigue life testing, parallel cracking of the coating occurred (Figure 11).

As the test temperatures of 20,100 , and $200 \mathrm{C}$ increased along with effects on the mechanical properties of $\mathrm{BM}$ and $\mathrm{BM}+\mathrm{GO}$ specimens, there was a typical decrease in yield stress, short-term tensile strength, and Young's modulus. The GO coating at elevated temperature acted as a thermal barrier causing an increase in the temperature of the samples at the break point of $9.4 \%$ (Figure 6).

Fatigue tests of the samples for the assumed maximum cycle stress levels confirmed insignificant differences in the durability of $\mathrm{BM}$ and $\mathrm{BM}+\mathrm{GO}$ samples at $20^{\circ} \mathrm{C}$ (Figure 7). A decrease in the fatigue life of $\mathrm{BM}$ and $\mathrm{BM}+\mathrm{GO}$ samples occurred at $100^{\circ} \mathrm{C}$; differences reached $77 \%$ depending on the stress level of the fatigue cycle. The resulting fatigue damage at the highest maximum cycle stress $\sigma_{\max }=540 \mathrm{MPa}$ led to an $8 \%$ reduction in the life 
difference of $\mathrm{BM}$ and $\mathrm{BM}+\mathrm{GO}$ specimens. On the other hand, the fatigue cracking of the specimens at the lowest fatigue cycle stress $\sigma_{\max }=370 \mathrm{MPa}$ developed in a stable manner, and thus the difference in durability was $77 \%$.

The decrease in fatigue life of the BM + GO samples tested at 20 and $100{ }^{\circ} \mathrm{C}$ occurred at all stress levels in the maximum fatigue cycle. However, at $200{ }^{\circ} \mathrm{C}$, the fatigue life of $\mathrm{BM}+\mathrm{GO}$ specimens was higher than that of BM specimens at maximum cycle stress levels $\sigma_{\max }=370$ and $420 \mathrm{MPa}$. Undoubtedly, this is a surprising result, but it is probably related to the change in properties of the GO layer (at the highest temperature of the tests, $200{ }^{\circ} \mathrm{C}$ ) and concerns a more favorable system of residual stresses occurring in the GO layer.

After analyzing the test results, it should be noted that the graphene oxide coating alone deposited on the steel did not unequivocally increase its fatigue life. Therefore, it is proposed that an additional strengthening treatment be carried out such as mechanical shot peening, which allows the deposited graphene oxide coating to be introduced into the surface layer and takes advantage of the unique properties of graphene to unequivocally increase durability, as the authors presented in [12].

\section{Conclusions}

The analysis of the results of investigations into the influence of the coating of deposited graphene oxide on the fatigue life of austenitic steel 1.4541 in different temperature ranges showed the following.

(1) Decrease (at the limit of statistical error) of tensile strength Rm by $1.53-2.56 \%$, yield strength Re by $2.97-5.65 \%$ and Young's modulus E by $2.93-8.89 \%$ for samples with a deposited graphene oxide layer (BM + GO) in comparison with untreated samples (BM).

(2) Increase in temperature of BM + GO samples during breaking of $9.4 \%$ in static tensile tests and $3-26 \%$ in fatigue tests.

(3) Decrease in fatigue life of BM + GO specimens compared to BM specimens regarding temperature stress level, at respective levels of

- $\quad 20{ }^{\circ} \mathrm{C}: 12 \%$ for $370 \mathrm{MPa}, 14 \%$ for $420 \mathrm{MPa}, 2 \%$ for $500 \mathrm{MPa}$ and

○ $\quad 100{ }^{\circ} \mathrm{C}: 77 \%$ for $370 \mathrm{MPa}, 37 \%$ for $420 \mathrm{MPa}, 8 \%$ for $500 \mathrm{MPa}$.

(4) Increase in fatigue life at $200{ }^{\circ} \mathrm{C}$ of $\mathrm{BM}+\mathrm{GO}$ samples by $135 \%$ and $21 \%$ at nominal stress amplitude of 370 and $420 \mathrm{MPa}$, respectively.

(5) The formation of faults at the lateral edge for BM specimens, which may be due to higher surface roughness.

(6) Parallel cracking of graphene flakes on the steel surface during fatigue tests.

\section{Patents}

The processing of elements presented in this work consisting of plasma cleaning and surface activation, application of graphene oxide, vacuum drying, and mechanical shot peening was called hybrid graphene treatment and is presented in patent application P. 438715.

Author Contributions: Conceptualization, B.N.; methodology, B.N.; formal analysis, B.N., Z.B., P.B. and A.B.; investigation, B.N., Z.B., P.B. and A.B.; resources, B.N., Z.B., A.B., P.B. and Z.M.; writing—original draft preparation, B.N.; writing—review and editing, B.N., Z.B., A.B., P.B. and Z.M.; visualization, B.N., P.B. and A.B.; supervision, B.N.; project administration, B.N.; funding acquisition, B.N. All authors have read and agreed to the published version of the manuscript.

Funding: This work was partly supported by the grant of the National Science Centre in Poland, Miniature 3, No 2019/03/X/ST8/01698. Investigation of the effect of deposited graphene oxide coating on fatigue life of austenitic steel 1.4541 in different temperature ranges.

Institutional Review Board Statement: Not applicable.

Informed Consent Statement: Not applicable.

Data Availability Statement: Data are contained within the article. 
Conflicts of Interest: The authors declare no conflict of interest.

\section{References}

1. Nasiłowska, B.; Bogdanowicz, Z.; Wojucki, M.; Bartosewicz, B.; Djas, M. Corrosion Protection for S235 JR Steel with Graphene Oxide. In Proceedings of the 12th International Scientific Conference Intelligent Technologies in Logistics and, Mechatronics Systems, ITELMS, Paneveżys, Lithuania, 26-27 April 2018; pp. 213-218.

2. Demir, K.; Gavgali, E.; Yetim, A.F.; Akpinar, S. The effects of nanostructure additive on fracture strength in adhesively bonded joints subjected to fully reversed four-point bending fatigue load. Int. J. Adhes. Adhes. 2021, 110, 102943. [CrossRef]

3. Rafiee, M.A.; Rafiee, J.; Srivastava, I.; Wang, Z.; Song, H.; Yu, Z.-Z.; Koratkar, N. Fracture and fatigue in graphene nanocomposites. Small 2010, 6, 179-183. [CrossRef] [PubMed]

4. Li, L.; Zheng, Q.; Han, B.; Ou, J. Fatigue behaviors of graphene reinforcing concrete composites under compression. Int. J. Fatigue 2021, 151, 106354. [CrossRef]

5. Yavari, F.; Rafiee, M.A.; Rafiee, J.; Yu, Z.-Z.; Koratkar, N. Dramatic Increase in Fatigue Life in Hierarchical Graphene Composites. ACS Appl. Mater. Interfaces 2010, 2, 2738-2743. [CrossRef] [PubMed]

6. Najafi, F.; Wang, G.; Cui, T.; Anand, A.; Mukherjee, S.; Filleter, T.; Sain, M.; Singh, C.V. Fatigue resistance of atomically thin graphene oxide. Carbon 2021, 183, 780-788. [CrossRef]

7. Wang, J.; Li, Z.; Fan, G.; Pan, H.; Chen, Z.; Zhang, D. Reinforcement with graphene nanosheets in aluminum matrix composites. Scr. Mater. 2012, 66, 594-597. [CrossRef]

8. Saedi, M.; Mohseni, S.M.; Groot, I.M.N. Thermodynamic analysis of graphene CVD grown on liquid metal: Growth on liquid metallic gallium or solid gallium oxide skin? Mater. Chem. Phys. 2022, 275, 125203. [CrossRef]

9. Takai, K.; Tsujimura, S.; Kang, F.; Inagaki, M. Graphene Preparations, Properties, Applications, and Prospects; Elsevier: Amsterdam, The Netherlands, 2019; p. 620. ISBN 9780128195772.

10. Maruyama, T. Copper oxide thin films prepared by chemical vapor deposition from copper dipivaloylmethanate. Sol. Energy Mater. Sol. Cells 1998, 56, 85-92. [CrossRef]

11. Nasiłowska, B.; Bogdanowicz, Z.; Hincza, K.; Mierczyk, Z.; Gózdz, S.; Djas, M.; Kowiorski, K.; Bombalska, A.; Kowalik, A. Graphene Oxide Aerosol Deposition and its Influence on Cancer Cells. Preliminary Results. Materials 2020, 13, 4464. [CrossRef] [PubMed]

12. Nasiłowska, B.; Bogdanowicz, Z.; Kłysz, S.; Baran, M.; Lisiecki, J.; Mońka, G.; Bartosewicz, B.; Komorek, Z.; Bombalska, A.; Mierczyk, Z. Fatigue Life of Austenitic Steel 304 Bolts Strengthened by Surface Treatment with Graphene Oxide Layer and Surface Shot Peening. Materials 2021, 14, 6674. [CrossRef] [PubMed]

13. Jagiełło, J.; Chlanda, A.; Baran, M.; Gwiazda, M.; Lipińska, L. Synthesis and Characterization of Graphene Oxide and Reduced Graphene Oxide Composites with Inorganic Nanoparticles for Biomedical Applications. Nanomaterials 2020, 10, 1846. [CrossRef] [PubMed]

14. Kalela, N.; Darpe, A.; Bijwe, J. Low pressure plasma induced surface changes of some stainless steels. Surf. Coat. Technol. 2021, 425, 127700. [CrossRef]

15. Sönmez, T.; Fazeli Jadidi, M.; Kazmanli, K.; Birer, Ö.; Ürgen, M. Role of different plasma gases on the surface chemistry and wettability of RF plasma treated stainless steel. Vacuum 2016, 129, 63-73. [CrossRef]

16. Tian, Y.; Bi, Z.; Cui, G. Study on the Corrosion Resistance of Graphene Oxide-Based Epoxy Zinc-Rich Coatings. Polymers 2021, 13, 1657. [CrossRef] [PubMed]

17. Kocanda, S. Fatigue Failure of Metals; Springer: Dordrecht, The Netherlands, 1978; pp. 1-368. 